\title{
Passivity based Approach for the Level Control of Spherical Tank Process
}

\author{
Priya $\mathrm{C}^{*}$ and Lakshmi Ponnnusamy $\$$ \\ *Assistant Professor, Department of Electronics and Instrumentation Engineering, Sri Sai Ram \\ Engineering College, Chennai, Tamil Nadu, India \\ ${ }^{\$}$ Professor, Department of Electrical and Electronics Engineering, College of Engineering, Anna \\ University, Chennai, Tamil Nadu, India
}

(Received 30 October 2019, accepted 8 March 2020)

Doi: https://doi.org/10.36224/ijes.130101

\begin{abstract}
The aim of this paper is to obtain the mathematical model and the real time model of the Single Input Single Output (SISO) conical tank system. The experimental model is obtained from the open loop response in real time and the transfer function is obtained using the two point method. For the real time model, two different controllers namely Zeigler Nichols tuned PI controller and passivity based controller are designed and tested in simulation and the performance of both the controllers are tested for servo operation and regulatory operation. The designed controllers are tested in Simulation and the response is recorded. The simulation results shows that the Passivity based Controller works better for the spherical tank process.
\end{abstract}

Keywords: Passivity based controller, spherical tank system, system, PI Controller, Tyreus luyben tuning method, nonlinear system, first order plus dead time system

\section{Introduction}

Most of the chemical processes are nonlinear in nature. While there may be an extensive understanding of the behavior of non linear process, satisfactory methods of their control are still evolving. A common control problem in process industries is the control of fluid levels in storage tanks $[1,2]$. The level control becomes difficult due to the nonlinear shape of tank that is the rate of rise of water in the bottom part is high becomes slow in the middle portion and again becomes high in the top portion of the tank thus causing non linear rise in level in both the cases. Spherical tanks are used in gas plants as containment system for Liquefied Natural Gas (LNG) carriers.

The control aspects of spherical tank system using Internal Model Controller (IMC) and Fuzzy Logic Controller (FLC) has been discussed in real time [3, 4]. Digital PI controller has been designed for spherical tank process in real time [5]. The most popular controller used in industry is PI/PID controller due to their simplicity, performance robustness and availability of many simple tuning rules based on minimum plant model knowledge [6]. However the conventional tuning techniques lack the intelligence and flexibility which would increase the performance rate and also improve the stability and error criterion $[7,8]$.

$\mathrm{PBC}$ is a generic name given to a family of controller design techniques that achieves system stabilization via the route of passivation that is rendering the closed loop system passive with a desired storage function that usually qualifies as a lyapunov function for the stability analysis [9]. Passivity theory has been applied to electrical systems, mechanical systems, 
electromechanical systems [10], chemical processes [11] with good results. This paper attempts to design the passivity-based controller for the spherical tank system from the FOPDT model of the system to maintain the water level in the tank.

This paper is organized as follows. The mathematical model of spherical tank is presented in section 2. Experimental setup and system identification is given in section 3 . Controller design is discussed in section 4. Simulation results of spherical tank is discussed in section 5 . Finally section 6 concludes the paper.

\section{Process description}

2.1. Mathematical model for spherical tank system

In this section the mathematical model of the spherical tank process is obtained. The schematic diagram of spherical tank system is shown in Figure 1.

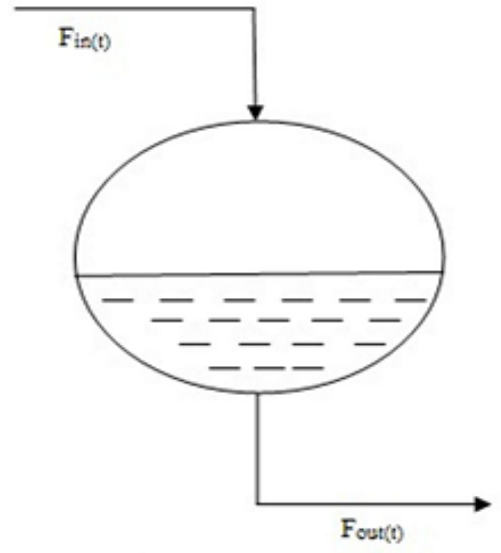

Figure 1: Schematic diagram of spherical tank system

$F_{\text {in }}(t)$-input flow rate $\mathrm{cm} 3 / \mathrm{sec}$

$\mathrm{F}_{\text {out }}(\mathrm{t})$ - output flow rate $\mathrm{cm} 3 / \mathrm{sec}$

Using the law of conservation of mass,

$$
\begin{aligned}
& F_{\text {in }}(t)-F_{\text {out }}(t)=S(h(t)) \frac{d h(t)}{d t} \\
& S(h(t))=\pi\left(2 R h(t)-h^{2}(t)\right) \\
& F_{\text {out }}(t)=C_{p} \sqrt{2 g h(t)}
\end{aligned}
$$

where,

$\mathrm{h}(\mathrm{t})=$ liquid level

$\mathrm{S}(\mathrm{h}(\mathrm{t}))=$ transverse section of the tank, which changes according to the liquid level

$\mathrm{R}=$ radius of the spherical tank.

$\mathrm{g}=$ gravitational constant 
the orifice.

$C_{p}=C_{d} a$, where, $\mathrm{C}_{\mathrm{d}}=$ discharge coefficient of the valve and a $=$ cross sectional area of

Substituting equations (2) and (3) in equation (1) and linearising the nonlinear model, final system is converged to the form

$$
\frac{K}{\tau s+1}
$$

where,

Time constant,

$$
\begin{array}{cl}
\text { process gain, } & K=\frac{\sqrt{2 R h_{0}(t)}}{C_{p} g} \\
& \tau=\frac{\pi \sqrt{2 g h_{0}(t)}\left(2 R h_{0}(t)-h_{0}{ }^{2}(t)\right)^{2}}{C_{p} g}
\end{array}
$$

With the delay $\theta$ in the process, the transfer function becomes

$$
G(s)=\frac{K e^{-\theta s}}{\tau s+1}
$$

\section{Experimental setup and system identification}

The block diagram of a experimental setup of the spherical tank system is shown in Figure 2[12]. It consists of a spherical tank, variable speed pump, rotameter is used for inflow measurement, Differential Pressure Transmitter (DPT) for level measurement, I/V converter, interface to PC using USB based DAQ, V/I converter, I/P converter, and a compressor to operate pneumatic control valve. The height and the diameter of the spherical tank is $48 \mathrm{~cm}$ and the diameter of the outlet pipe from the tank is $1.5 \mathrm{~cm}$.

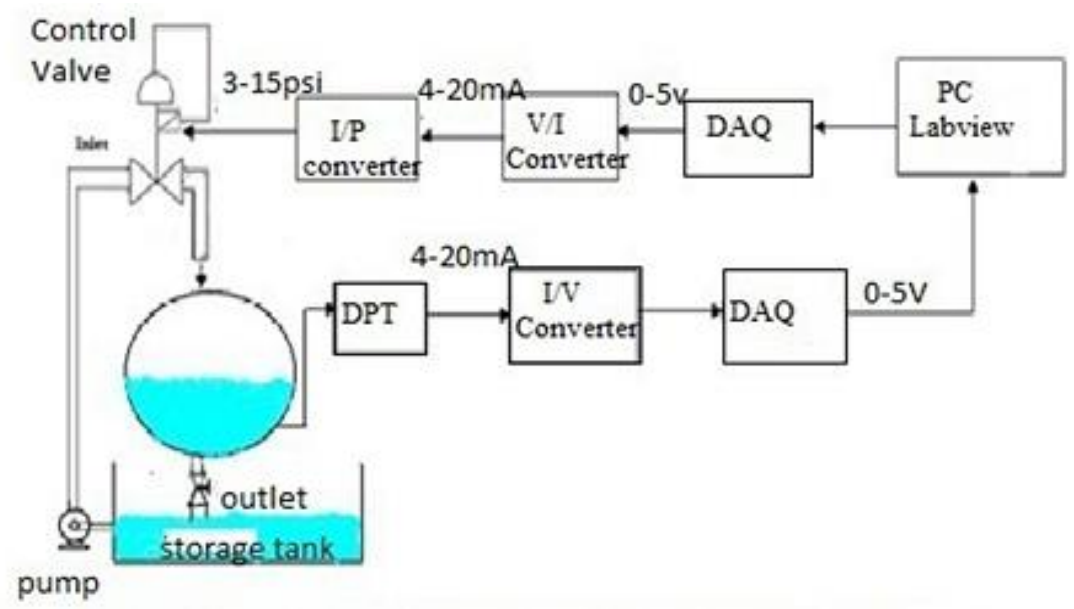

Figure 2: Block diagram of real time experiment setup of spherical tank

The experimental data are approximated to be a FOPDT model and the transfer function of the spherical tank system for the operating condition of $25 \mathrm{~cm}$ is given below in Equation 8 . 


$$
G_{p}(s)=\frac{0.28 e^{-39 s}}{500 s+1}
$$

\section{Controller design}

The PI controller parameters are tuned by using ZN method of tuning based on ultimate gain and ultimate period. According to the dead time to time constant ratio $\left(\theta / \tau_{\mathrm{p}}\right)$, appropriate tuning rule, Tyreus Luyben tuning rule for PI controller is also chosen [13]. These tuning rules are very popular in industry as it is a simple method and required very little information about the process. The PI tuning parameters for $\mathrm{ZN}$ method is $\mathrm{K}_{\mathrm{p}}=36$ and $\mathrm{T}_{\mathrm{i}}=138$ and for Tyreus Luyben method $\mathrm{K}_{\mathrm{p}}=25$ and $\mathrm{T}_{\mathrm{i}}=364$.

The PBC equations are discussed in detail in [14] and the final controller expression is restated as

$$
\left\{\begin{array}{c}
U=\frac{1}{C}\left[-D\left(x_{1}-x_{1 d}\right)-R_{2} \int\left(x_{1}-x_{1 d}\right) d t-R_{2}\left(x_{2}-\overline{x_{2}}\right)\right]+\bar{u} \\
x_{1 d}^{\circ}=-\left(D+\frac{A}{x_{1}}\right) x_{1 d}+D \overline{x_{2}}+R_{1}\left(x_{1}-x_{1 d}\right)
\end{array}\right.
$$

The parameters A, C and D are calculated from the system model [14] and the other PBC parameters are set to $\mathrm{R}_{1}=0.15, \mathrm{R}_{2}=0.0015$ and $\mathrm{R}_{3}=0, \bar{x}_{2}=5$ for spherical tank system.

\section{Results and discussion}

The closed loop response of the spherical tank system tuned by ZN based PI, Tyreus Luyben tuning method-based PI and Passivity based controller are given in Figure 3. Then for the servo operation the discussed controllers are tested for a sequence of 2 step changes. After reaching a steady state of $25 \mathrm{~cm}$ a positive step change of $+20 \%$ at 1200 second and a negative step change of $-20 \%$ at 2400 seconds are applied respectively. The variations of level with time for the ZN/PI, Tyreus Luyben/PI and Passivity based controller are shown in Figure 4 for servo operation. Similarly a disturbance in load of $+20 \%$ is applied at 2200 secs to the spherical tank system with ZN/PI, Tyreus Luyben/PI, and Passivity based controller which is shown in Figure 5 .

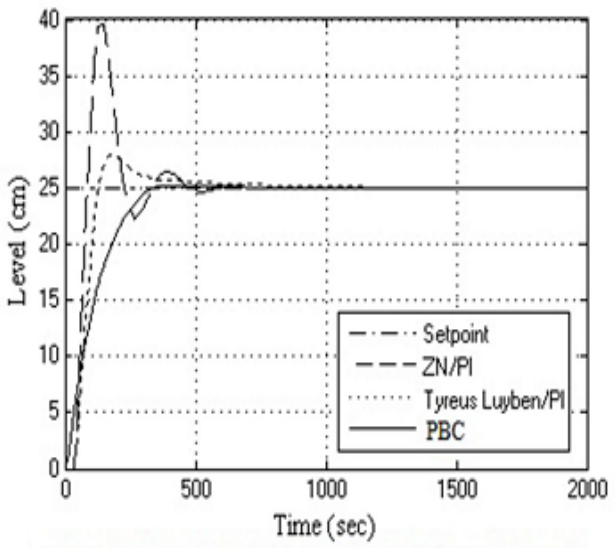

Figure 3(a): Closed loop response of ZN/PI, Tyrus Luyben/PI and $\mathrm{PBC}$ for the set point tracking of $25 \mathrm{~cm}$

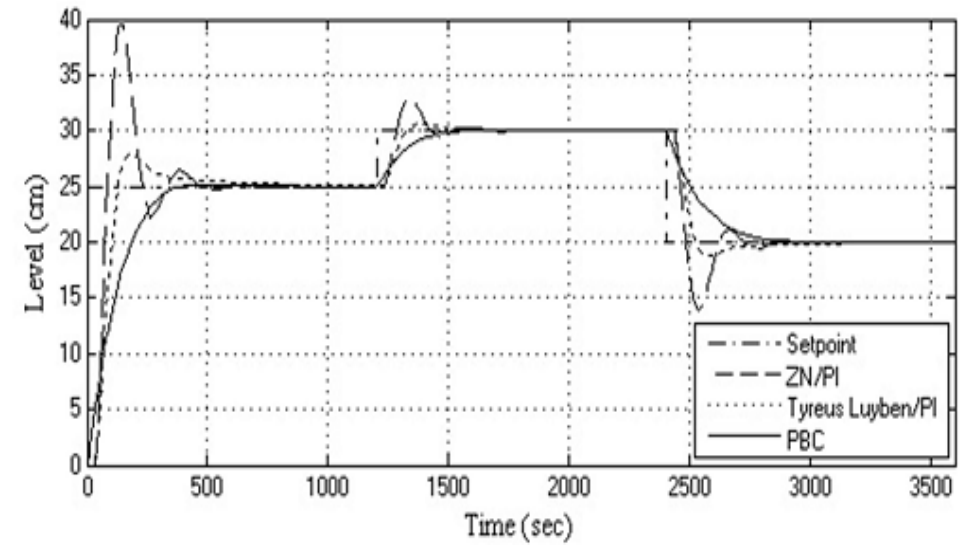

Figure 3(b): Servo response of ZN/PI, Tyrus Luyben/PI and PBC for change in set point of $+20 \%$ and $-20 \%$ applied at $1200,2400 \mathrm{~s}$ 


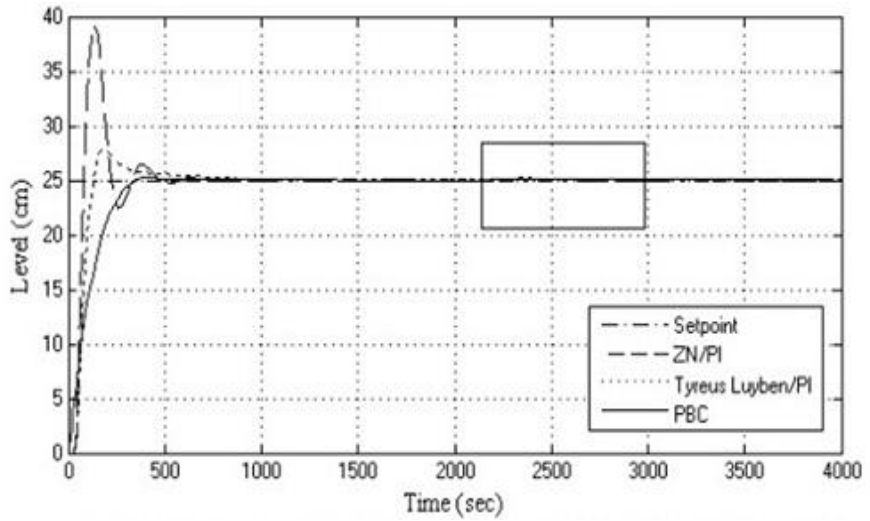

Figure 4(a): Regulatory response of ZN/PI, Tyrus Luyben/PI and PBC for load change of $+20 \%$ applied at 2200 secs

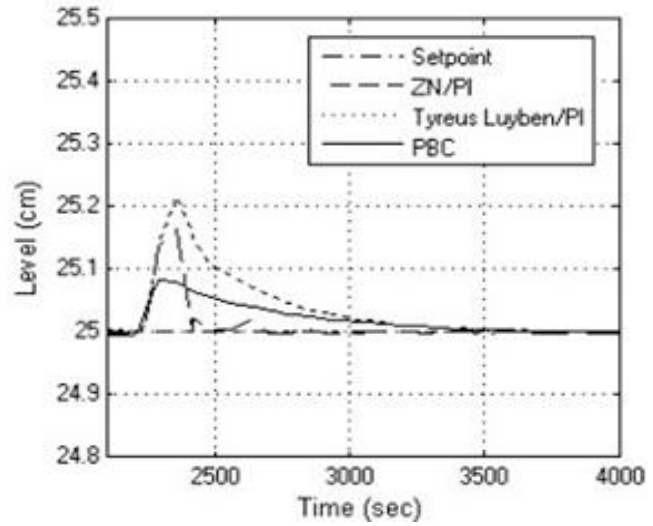

Figure 4(b): Expanded regulatory response

Table 1(a) gives the time domain specifications and performance index values, normalized ITAE values for the operating condition of $25 \mathrm{~cm}$ level and Table 1(b) gives the normalized ITAE values for the servo response and regulatory response.

Table 1: (a) Time domain parameters and performance index values for the set point of $25 \mathrm{~cm}$ obtained through MATLAB simulation, (b) Performance index values for servo and regulatory response obtained in MATLAB simulation

\begin{tabular}{|l|c|c|c|}
\hline \multirow{2}{*}{ Controller } & \multicolumn{3}{|c|}{ Closed loop response } \\
\cline { 2 - 4 } & \multicolumn{3}{|c|}{ Setpoint $=25 \mathrm{~cm}$} \\
\cline { 2 - 4 } & $\begin{array}{c}\text { Maximum } \\
\begin{array}{c}\text { Peak } \\
\text { Overshoot } \\
\left(\mathrm{M}_{\mathrm{p}} \%\right.\end{array}\end{array}$ & $\begin{array}{c}\text { Settling } \\
\text { time }\left(\mathrm{t}_{\mathrm{t}}\right) \\
\mathrm{sec}\end{array}$ & $\begin{array}{c}\text { Normalized } \\
\text { ITAE }\end{array}$ \\
\hline ZNPI & 58 & 580 & 180 \\
\hline Tyreus Luyben PI & 11.6 & 700 & 174 \\
\hline $\begin{array}{l}\text { Passivity Based } \\
\text { Control }\end{array}$ & 0.92 & 480 & 133 \\
\hline
\end{tabular}

\begin{tabular}{|l|c|c|}
\hline \multirow{2}{*}{ Controller } & \multicolumn{2}{|c|}{ Nomalised ITAE } \\
\cline { 2 - 3 } & Servo response & $\begin{array}{c}\text { Regulatory } \\
\text { response }\end{array}$ \\
\cline { 2 - 3 } & $\begin{array}{c}+20 \% \text { at } 1200 \text { secs } \\
\text { and }-20 \% \text { at } 2400 \\
\text { secs. }\end{array}$ & $\begin{array}{c}+20 \% \\
\text { disturbance }\end{array}$ \\
\hline ZNPI & 1213 & 102 \\
\hline Tyreus Luyben PI & 1004 & 133 \\
\hline $\begin{array}{l}\text { Passivity Based } \\
\text { Control }\end{array}$ & 959 & 94 \\
\hline
\end{tabular}

\section{Conclusions}

This paper work demonstrates the applicability of PBC for the spherical tank process. As seen from the simulation results, $\mathrm{ZN}$ tuned PI controller accounts for the largest amount of overshoot with the settling time of 580 seconds. and also performance index values for Integral Time Absolute Error (ITAE) is found to be more in the case of closed loop response and servo response. The Tyreus Luyben PI controller has less overshoot compared to $\mathrm{ZN}$ tuned PI controller but more overshoot compared to passivity based controller with the highest settling time and also it has more ITAE values in the case of regulatory response compared to $\mathrm{ZN}$ tuned PI controller and Passivity based controller. Passivity based controller is found to have very less overshoot with the settling time of 480 seconds and also performance index values are found to be very less compared to Tyreus Luyben/PI and ZN/PI controller. 


\section{References}

[1] H, M. Falkus and AAH Damen, "Robust Parameter Estimation applied to a water vessel Process", Proc. of IFAC World Congress, Sydney, 5, 59-62 1993

[2] AA Zahrani and M NoorWali, "Experimental Application of some Advance Algorithms for Average Level Control”, Control and Computers, 23, 3, 79-83, 1995

[3] S Nithya, N Sivakumaran, T Balasubramanian and N Anantharaman, "Model based controller design for spherical tank process in real time ", IJSSST, 9, 4, 25-31, 2008

[4] S Nithya, Abhay Singh Gour, N Sivakumaran, T K Radhakrishnan, T Balasubramanian and N Anantharaman, "Design of Intelligent controller for Non-Linear Processes", Asian Journal of Applied Sciences, 1, 1, 33-45, 2008

[5] G Sakthivel, T S Anandhi and S P Natarajan, "Modeling and Real Time Implementation of Digital Pi Controller for a Non Linear Process", Journal of Innovative Research in Engineering and Sciences, 2, 5, 274-290, 2011

[6] JG Ziegler and NB Nichols, “Optimum Settings For Automatic Controllers”, Trans. Amer. Soc.Mech. Eng., 64, 8, 759-768, 1942

[7] Su Whan Sung, In-Beum Lee and Jitae Lee, "Modified Proportional-Integral Derivative (PID) Controller and a New Tuning Method for the PID Controller", Ind. Eng. Chem. Res., 34, 11, 41274132

[8] Mehrdad Salami and Greg Cain, "An adaptive PID controller based on Genetic Algorithm processor, Genetic Algorithms in engineering systems: Innovations and applications", IEEE, Conference Publication, 414, 88-93, 1995

[9] C Batle, A Doria-Cerezo, G. Espinosa-Perez and R. Ortega, "Simultaneous Interconnection and Damping Assignment Passivity-Based Control: Two Practical Examples", $3^{\text {rd }}$ IFAC Workshop on Lagrangian and Hamiltonian Methods for Nonlinear Control, Nogoya, 93-98, 2006

[10] R Ortega, A Loria, P J Nicklarron and H Sira-Ramirez, "Passivity-based control of Euler-Lagrange Systems: Mechanical, Electrical and Electromechanical Applications", Communications and Control Engineering Series Springer: Berlin, 1998.

[11] H Sira, and M Angulo, "Passivity-based control of Nonlinear Chemical Processes", International Journal of Control, 68, 5, 971-996, 1997

[12] C Priya and P Lakshmi, "Particle swarm optimization applied to real time control of spherical tank system", International Journal of Bio Inspired Computation, 4(4), 206- 216, 2012

[13] T Thyagarajan, and Yu Cheng-Ching, "Improved autotuning using the shape factor from Relay feedback", Ind. Eng. Chem. Res., 42(20), 4425-4440, 2003

[14] Priya Chandrasekar and Lakshmi Ponnusamy, "Comparative study of controllers for a variable area MIMO interacting nonlinear system”, International Journal of Engineering and Technology, 6, 1, 227-235, 2014 